\title{
Impact of Mediterranean Diet on Cancer: Focused Literature Review
}

\author{
YORAM BARAK $^{1}$ and DANA FRIDMAN ${ }^{2}$ \\ ${ }^{1}$ The University of Otago Medical School, Dunedin, New Zealand; \\ ${ }^{2}$ School of Design, Victoria University of Wellington, Wellington, New Zealand
}

\begin{abstract}
Background: Cancer is a major public health problem worldwide, and the number of incident cases increases every year expected to reach 17.1 million a year by 2020. There is evidence that people who adhere to the Mediterranean Diet (MediD) have lower incidence of cancer. However, cancers' location and culture studies seem to affect the MediD impact. We aimed to review these discrepant findings. Materials and Methods: A critical review from a focused literature search was conducted. A literature search of controlled trials from: EMBASE (1970-), MEDLINE (1950-) and PsycINFO (1960-) was undertaken. Two authors (DF and $Y B)$ independently extracted the data. Results: Out of 785 abstracts identified only 583 publications focused solely on MediD and cancer. Of these, 46 were clinical trials published since 2007. Twenty-eight trials with a total of 570,262 participants are included in accordance with inclusion criteria. Only four reported the MediD does not reduce the risk of cancer. Of the negative studies, three were undertaken in nonMediterranean populations. Cancers of the digestive tract were studied in 11 studies. Except for pancreatic cancer, all other sites along the digestive tract demonstrated significantly reduced rate with the MediD. Conclusion: The MediD is associated with reduction in overall cancer rates as well as significantly lower rates of digestive tract cancers. These effects may be accentuated in the Mediterranean countries themselves. Further studies are needed to support or refute the effects of the MediD on other cancer types.
\end{abstract}

Cancer is a major public health problem worldwide, and the number of incident cases increases every year. According to

This article is freely accessible online.

Correspondence to: Assoc. Prof. Yoram Barak, MD, MHA., Dept Psychological Medicine, Dunedin School of Medicine, PO Box 913, Dunedin, New Zealand. E-mail: Yoram.Barak@otago.ac.nz

Key Words: Mediterranean diet, cancer, MediD, review.
GLOBOCAN, 14.1 million incident cases were recorded in 2012 (1). The World Health Organisation estimates that these numbers will grow to 17.1 million a year by 2020 (2). There is evidence that people who adhere to the Mediterranean Diet (MediD) have lower incidence of cancer $(3,4)$.

MediD includes plant foods such as fruits, vegetables, cereals, legumes, nuts, seeds, and olive oil. The diet also contains dairy products with recommended low consumption of milk and high consumption of cheese and yoghurt, moderate consumption of fish, eggs, low amounts of red meat consumption, and low to moderate consumption of wine, mainly with meals. (4).

It is important to recognise the different relationships between MediD and cancer across studies and types of cancer. For example, there is evidence that MediD can mediate the effects of smoking on colorectal cancer (5), and is associated with more than $50 \%$ reduction in oropharyngeal, oesophageal and laryngeal cancer risks 6). Moreover, MediD is associated with lower risk of breast cancer amongst postmenopausal women (7). However, there is no association between MediD and breast cancer amongst premenopausal women (7).

Therefore, there is a need for a critical review of the literature in order clarify the effects of MediD on cancer overall and across studies, recognise gaps in the research, and gather insights into how we might design interventions for the prevention of cancer.

\section{Materials and Methods}

Approach to reviewing process. This was based in part on the approach recently advocated by Catts and O'Toole (8). Briefly, the clinical issue reviewed was selected because the authors considered it decidedly relevant to clinical practice and likely to impact on health outcomes and its contentious nature is reflected in divergences across guidelines and clinical practice. This critical review results from a of focused literature search. Although a systematic review would have been desirable, a critical review approach was the feasible way to integrate the literature. Selection of material was strongly weighted by relevance. 
The following bibliographic databases: EMBASE (1970- ) and MEDLINE (1950- ) were searched. Bibliography of all studies and relevant reviews were screened. Two review authors (DF and YB) independently extracted the data.

Inclusion criteria for studies to be analysed in the present review were: (1) controlled trials (CTs), (2) Mediterranean diet the only lifestyle "intervention," (3) use of rating scales to quantify adherence to the MediD, (4) sample size >200, (5) OR (Odds Ratio) or HR (Hazard Ratio) reported as outcome and (5) publication in the last 10 years. Exclusion criteria: (1) review or meta-analysis (2) cancer not primary outcome and (3) number of cases not reported.

\section{Results}

Our search identified 785 abstracts, but only 583 publications focused solely on the MediD and cancer. Of these 46 were clinical trials published since 2007.

In the present review 28/46 trials with a total of 570,262 participants are included in accordance with inclusion criteria. The European Prospective Investigation into Cancer and Nutrition (EPIC; 9) was counted only once in contributing to the total number of participants in the present review. Due to clinical heterogeneity, few direct comparisons were possible. The main outcome in the published studies was OR or HR. See Table I for details of studies reviewed.

The first study to assess the effects of the MediD was published in 1985. The authors reported on variations in cancer mortality in Italy suggesting:" It is conceivable that dietary factors may also explain some of the differences. However, at present, there is no obvious general explanation for this quite peculiar geographical distribution of cancer mortality within a single country..." (10). Since then hundreds of studies focused on the role of the MediD in reducing cancer rates.

In the present review of 28 studies analyzed and 4 of these studies reported that adherence to the MediD does not reduce the risk of cancer $(6-9,13,14,24-43)$. It is important to note that of the negative studies three were undertaken in nonMediterranean populations; USA, Sweden and Holland (11-14).

Cancers of the digestive tract were studied in 11 different studies including nasopharyngeal cancers, gastric, pancreatic and colorectal. It is of interest to note that except for pancreatic cancer all other sites along the digestive tract demonstrated significantly reduced rate of cancers with adherence to the MediD. The largest effect (smallest OR) in the present analysis was indeed for oral cavity and pharyngeal cancer (OR: 0.20).

In addition, breast cancer studies are the largest single cancer type studied in the present analysis. There were 7/28 studies focusing on breast cancer of which two were based on data from the EPIC project. In two of the seven studies non-significant reductions in OR or HR were reported, in three studies reduction in risk was minimal $(\mathrm{OR}=0.88-0.94)$. Moreover, in two of the studies the significant effects of the
MediD were demonstrated only for estrogen receptor negative tumors.

\section{Discussion}

"Cancer is a preventable disease that requires major lifestyle changes" declared Anand and colleagues in 2008. Each year 12.7 million people discover they have cancer and 7.6 million people die from a disease commonly believed to be preventable. The great majority of cancers have their roots in the environment and lifestyle. Lifestyle factors for which abundant public and scientific awareness is raised include: cigarette smoking, diet, alcohol, sun exposure, environmental pollutants, infections, stress, obesity, and physical inactivity (15). The evidence indicates that of all cancer-related deaths, as many as $30-35 \%$ are linked to diet (16). In a more recent global review the population attributable fraction - the epidemiological measure that quantifies this potential reduction in incidence - was reported for most cancer sites. Studies distribution was not uniform, with many articles reporting cancer population attributable fractions for and tobacco, but fewer reporting population attributable fractions for dietary factors $(17,18)$. In the present review, we aimed to assess the benefits attributed to the MediD in reducing the risk of developing cancer.

As seven of the studies herein analyzed are from the EPIC database that is the largest database available to date focusing on "cancer and nutrition..." we need to briefly recap the principle components of the EPIC project. Conceptualized and initiated in the early 1990's the EPIC study was originally conceived as a multi-centre prospective cohort study designed to investigate the relation between diet, nutritional and metabolic characteristics, various lifestyle factors and the risk of cancer. The study was based in 22 collaborating centres in nine European countries and includes populations characterized by large variations in dietary habits and cancer risk.

It was planned to include around 400,000 middle-aged men and women and it was expected that about 23,000 cancer cases will be identified during the first 10 years of follow-up (19). By now the EPIC study cohort includes over half a million participants, from 10 countries in Europe recruited between 1991 and 2000 with a mean follow-up of almost 15 years (20). In the EPIC study the overall cancer risk was found to be reduced with an HR of 0.88 when 25,623 cancers were analyzed.

The present analysis supports previous reports on the association between the MediD and reduction in overall cancer rates as well as reductions in digestive tract cancers. Findings are not as clear-cut when data is derived from nonMediterranean countries or for cancer sites other than the digestive tract. The reproductive hormonally affected cancers (breast, endometrial and prostate) were reported to be 
Table I. Summary of studies reviewed.

\begin{tabular}{|c|c|c|c|c|c|}
\hline References & Study design & $\begin{array}{c}\text { Sample size: } \\
\text { cases and controls }\end{array}$ & Cancer type & Outcome & Comments \\
\hline Stojanovic et al. (24) & Case-Control & 446 & Gastric & OR: 0.70 & \\
\hline van den Brandt \& Schulpen (14) & Case-Cohort & 3,986 & Breast & OR: $0.94 \mathrm{NS}$ & $\begin{array}{l}\text { Significant effect for } \\
\text { ER negative tumors }\end{array}$ \\
\hline Molina-Montes et al. (13) & Prospective cohort study & 865 & Pancreatic & HR: $0.99 \mathrm{NS}$ & EPIC study \\
\hline Turati et al. (25) & Case-Control & 792 & Nasopharyngeal & OR: 0.66 & \\
\hline Rosato et al. (26) & Case-Control & 10,549 & Colorectal & OR: 0.52 & \\
\hline Giraldi et al. (27) & Case-Control & 933 & Head and Neck & OR: 0.61 & \\
\hline Hodge et al. (28) & Case- Series & 403 & Lung & HR: 0.64 & $\begin{array}{l}\text { Especially for } \\
\text { current smokers }\end{array}$ \\
\hline Toledo et al. (29) & Case-Control & 4,152 & Breast & HR: 0.32 & The PREDIMED study \\
\hline Filomeno et al. (30) & Case-Control & 5,079 & Endometrial & OR: 0.43 & \\
\hline Castello et al. (31) & Case-Control & 2034 & Breast & OR: 0.56 & $\begin{array}{l}\text { Significant effect for } \\
\text { ER negative tumors }\end{array}$ \\
\hline Filomeno et al. (6) & Case-Control & 2,846 & $\begin{array}{l}\text { Oral cavity and } \\
\text { pharyngeal }\end{array}$ & OR: 0.20 & \\
\hline Mourouti et al. (32) & Case-Control & 500 & Breast & OR: 0.91 & \\
\hline Grosso et al. (33) & Case-Control & 1014 & Colorectal & OR: 0.46 & \\
\hline Praud et al. (34) & Case-Control & 3627 & Gastric & OR: 0.78 & \\
\hline Buckland et al. (35) & Prospective cohort study & 477,312 & Bladder & HR: 0.84 & EPIC study \\
\hline Kenfield et al. (36) & Prospective cohort study & 4538 & Prostate & HR: 0.78 & \\
\hline Idilbi et al. (37) & Case-Control & 200 & Overall cancers & OR: 0.4 & \\
\hline Bosetti et al. (38) & Case-Control & 2,892 & Pancreatic & OR: 0.57 & \\
\hline Bamia et al. (39) & Prospective cohort study & 4355 & Colorectal & HR: 0.89 & EPIC study \\
\hline Möller et al. (12) & Case-Control & 2,590 & Prostate & OR: $1.07 \mathrm{NS}$ & \\
\hline Buckland et al. (40) & Prospective cohort study & 335,062 & Breast & $\mathrm{HR}=0.94$ & $\begin{array}{l}\text { EPIC study. } \\
\text { Significant effect for } \\
\text { ER negative tumors. } \\
\text { Premenopausal women } \\
\text { NS. Postmenopausal } \\
\text { women }(\mathrm{HR}=0.80) \text {. }\end{array}$ \\
\hline Kontou et al. (35) & Case-Control & 500 & Colorectal & OR: 0.87 & \\
\hline Kontou et al. (41) & Case-Control & 500 & Colorectal & OR: 0.89 & \\
\hline Cade et al. (42) & Cohort Study & 33,731 & Breast & HR: 0.65 & \\
\hline Trichopoulou et al. (7) & Prospective cohort study & 14,807 & Breast & $\mathrm{HR}=0.88$ & $\begin{array}{c}\text { EPIC study. } \\
\text { Premenopausal women } \\
(\mathrm{HR}=1.01) . \text { Postmeno- } \\
\text { pausal women } \\
(\mathrm{HR}=0.78) .\end{array}$ \\
\hline Samoli et al. (43) & Case-Control & 433 & Upper Aerodigestive & act OR: 0.70 & \\
\hline Buckland et al. (9) & Prospective cohort study & 485,044 & Gastric & HR: 0.67 & EPIC study \\
\hline Benetou et al. (3) & Prospective cohort study & 25,623 & Overall cancers & HR: 0.88 & EPIC study \\
\hline Dalvi, Alison \& Pamela (11) & Case-Control & 949 & Endometrial & $\mathrm{OR}=1.4$ & \\
\hline
\end{tabular}

EPIC, European Prospective Investigation into Cancer and Nutrition. NS, Not statistically significant.

positively and negatively associated with the MediD. It is of interest to speculate on the highly positive effects of the MediD in Mediterranean countries. There are possibly additional variables and confounders that differentiate between the populations studied. Recent reports support the assertion that culturally specific diets may positively affect health. Three examples emphasize this concept: Chilli consumption in China, the Nordic diet and Asian flavonoids. The frequency of spicy food intake has recently been associated with a reduced risk of mortality in the Chinese population. A total 12,970 Chinese adults were followed for a median of 9 years. Chilli consumption was found to be inversely associated with the incidence of obesity (21). The Nordic Nutrition Recommendations were evaluated in a systemic manner to assess Health effects associated with foods characteristic of the Nordic diet. Based on 57 studies. There was suggestive evidence (low-grade) for whole grains protecting against colorectal cancer (22). The selection of a 
particular food plant, plant tissue or herb emulates its flavonoid composition. The lower risk of colon, prostate and breast cancers in Asians, who consume more vegetables, fruits and tea than populations in the Western hemisphere do, raises the question of whether flavonoid components mediate this protective effect (23).

We conclude that the MediD is associated with reduction in overall cancer rates as well as significantly lower rates of digestive tract cancers. These effects may be accentuated in the Mediterranean countries themselves. Further studies are needed to support or refute the effects of the MediD on other cancer types.

\section{Expert Commentary}

The MediD has been researched and assessed for approximately 40 years and over 1,500 publications attest to the interest it ignites. Much of our knowledge about this diet has come from studying populations restricted in geographical distribution. The realization that the MediD is still rapidly evolving as a nutritional intervention to reduce cancer rates is important.

As we were reminded, 2017 marks the 20th anniversary of the publication of the results of the Dietary Approaches to Stop Hypertension (DASH) Diet Study. Despite the impressive results, numerous surveys have shown that the DASH diet is underutilized among the tens of millions of US citizens who have hypertension and prehypertension. If we do not wish the MediD to suffer the same setbacks that the DASH does increased emphasis on educating providers (both in training and continuing medical education) may be helpful. Leaders of the community of providers who are committed to public health, we all have a responsibility to continue to emphasize healthy lifestyle habits, including the MediD eating plan, to our colleagues and patients.

\section{References}

1 Ferlay J, Soerjomataram I, Dikshit R, Eser S, Mathers C, Rebelo M, Parkin DM, Forman D and Bray F: Cancer incidence and mortality worldwide: sources, methods and major patterns in GLOBOCAN 2012. Int J Cancer 136: 359-386, 2015.

2 http://gco.iarc.fr/. The Global Cancer Observatory (GCO) is an interactive web-based platform presenting global cancer statistics to inform cancer control and research. IARC 2017.

3 Benetou V, Trichopoulou A, Orfanos P, Naska A, Lagiou P, Boffetta P, Trichopoulos D and Greek EPIC cohort: Conformity to traditional Mediterranean diet and cancer incidence: the Greek EPIC cohort. Br J Cancer 99: 191-195, 2008.

4 Dinu M, Pagliai G, Casini A and Sofi F: Mediterranean diet and multiple health outcomes: an umbrella review of meta-analyses of observational studies and randomised trials. Eur J Clin Nutr May $10,2017$.

5 Kontou N, Psaltopoulou T, Soupos N, Polychronopoulos E, Xinopoulos D, Linos A and Panagiotakos DB: The mediating effect of Mediterranean diet on the relation between smoking and colorectal cancer: a case-control study. Eur J Public Health 23: 742-746, 2013.

6 Filomeno M, Bosetti C, Garavello W, Levi F, Galeone C, Negri $\mathrm{E}$ and $\mathrm{La}$ Vecchia $\mathrm{C}$ : The role of a Mediterranean diet on the risk of oral and pharyngeal cancer. Br J Cancer 111: 981-986, 2014.

7 Trichopoulou A, Bamia C, Lagiou P and Trichopoulos D: Conformity to traditional Mediterranean diet and breast cancer risk in the Greek EPIC (European Prospective Investigation into Cancer and Nutrition) cohort. Am J Clin Nutr 92: 620-625, 2010.

8 Catts SV and O'Toole BI: The treatment of schizophrenia: Can we raise the standard of care? Aust N Z J Psychiatry 50: 11281138,2016

9 Buckland G, Agudo A, Luján L, Jakszyn P, Bueno-de-Mesquita HB, Palli D, Boeing H, Carneiro F, Krogh V, Sacerdote C, Tumino R, Panico S, Nesi G, Manjer J, Regnér S, Johansson I, Stenling R, Sanchez MJ, Dorronsoro M, Barricarte A, Navarro C, Quirós JR, Allen NE, Key TJ, Bingham S, Kaaks R, Overvad K, Jensen M, Olsen A, Tjønneland A, Peeters PH, Numans ME, Ocké MC, Clavel-Chapelon F, Morois S, Boutron-Ruault MC, Trichopoulou A, Lagiou P, Trichopoulos D, Lund E, Couto E, Boffeta P, Jenab M, Riboli E, Romaguera D, Mouw T and González CA: Adherence to a Mediterranean diet and risk of gastric adenocarcinoma within the European Prospective Investigation into Cancer and Nutrition (EPIC) cohort study. Am J Clin Nutr 91: 381-390, 2010.

10 Facchini U, Camnasio M, Cantaboni A, Decarli A and La Vecchia C: Geographical variation of cancer mortality in Italy. Int J Epidemiol 14: 538-548, 1985.

11 Dalvi TB, Canchola AJ and Horn-Ross PL: Dietary patterns, Mediterranean diet, and endometrial cancer risk. Cancer Causes Control 18: 957-966, 2007.

12 Möller E, Galeone C, Andersson TM, Bellocco R, Adami HO, Andrén O, Grönberg H, La Vecchia C, Mucci LA and Bälter K: Mediterranean Diet Score and prostate cancer risk in a Swedish population-based case-control study. J Nutr Sci 2: e15, 2013.

13 Molina-Montes E, Sánchez MJ, Buckland G, Bueno-deMesquita HB, Weiderpass E, Amiano P, Wark PA, Kühn T, Katzke V, Huerta JM, Ardanaz E, Quirós JR, Affret A, His M, Boutron-Ruault MC, Peeters PH, Ye W, Sund M, Boeing H, Iqbal K, Ohlsson B, Sonestedt E, Tjønneland A, Petersen KE, Travis RC, Skeie G, Agnoli C, Panico S, Palli D, Tumino R, Sacerdote C, Freisling H, Huybrechts I, Overvad K, Trichopoulou A, Bamia C, Vasilopoulou E, Wareham N, Khaw KT, Cross AJ, Ward HA, Riboli E and Duell EJ: Mediterranean diet and risk of pancreatic cancer in the European Prospective Investigation into Cancer and Nutrition cohort. Br J Cancer 116: 811-820, 2017.

14 van den Brandt PA and Schulpen M: Mediterranean diet adherence and risk of postmenopausal breast cancer: results of a cohort study and meta-analysis. Int J Cancer 140: 2220-2231, 2017.

15 Gillie O: The Scots' Paradox: Can Sun Exposure, or Lack of it, Explain Major Paradoxes in Epidemiology? Anticancer Res 32: 237-248, 2012.

16 Anand P, Kunnumakkara AB, Sundaram C, Harikumar KB, Tharakan ST, Lai OS, Sung B and Aggarwal BB: Cancer is a preventable disease that requires major lifestyle changes. Pharm Res 25: 2097-2116, 2008.

17 Ruggiero M, Ward E, Smith R, Branca JJV, Noakes D, Morucci G, Taubmann M, Thyer L and Pacini S: Oleic Acid, 
Deglycosylated Vitamin D-Binding Protein, Nitric Oxide: A Molecular Triad Made Lethal to Cancer. Anticancer Res 34: 3569-3578, 2014.

18 Whiteman DC and Wilson LF: The fractions of cancer attributable to modifiable factors: A global review. Cancer Epidemiol 44: 203-221, 2016.

19 Riboli E and Kaaks R: The EPIC Project: rationale and study design. European Prospective Investigation into Cancer and Nutrition. Int J Epidemiol 26: 6-14, 1997.

20 McKenzie F, Biessy C, Ferrari P, Freisling H, Rinaldi S, Chajès V, Dahm CC, Overvad K, Dossus L, Lagiou P, Trichopoulos D, Trichopoulou A, Bueno-de-Mesquita HB, May A, Peeters PH, Weiderpass E, Sanchez MJ, Navarro C, Ardanaz E, Ericson U, Wirfält E, Travis RC and Romieu I: Healthy Lifestyle and Risk of Cancer in the European Prospective Investigation Into Cancer and Nutrition Cohort Study. Medicine (Baltimore) 95: e2850, 2016.

21 Shi Z, Riley M, Taylor AW and Page A: Chilli consumption and the incidence of overweight and obesity in a Chinese adult population. Int J Obes (Lond) 41: 1074-1079, 2017.

22 Akesson A, Andersen LF, Kristjánsdóttir AG, Roos E, Trolle E, Voutilainen E and Wirfält E: Health effects associated with foods characteristic of the Nordic diet: a systematic literature review. Food Nutr Res 9: 57-78, 2013.

23 Kanadaswami C, Lee LT, Lee PP, Hwang JJ, Ke FC, Huang YT and Lee MT: The Antitumor Activities of Flavonoids. In Vivo 19: 895-909, 2005.

24 Stojanovic J, Giraldi L, Arzani D, Pastorino R, Biondi A, Persiani R, Boccia $S$ and Leoncini E: Adherence to Mediterranean diet and risk of gastric cancer: results of a casecontrol study in Italy. Eur J Cancer Prev 26: 491-496, 2017.

25 Turati F, Bravi F, Polesel J, Bosetti C, Negri E, Garavello W, Taborelli M, Serraino D, Libra M, Montella M, Decarli A, Ferraroni $\mathrm{M}$ and La Vecchia C: Adherence to the Mediterranean diet and nasopharyngeal cancer risk in Italy. Cancer Causes Control 28: 89-95, 2017.

26 Rosato V, Guercio V, Bosetti C, Negri E, Serraino D, Giacosa A, Montella M, La Vecchia C and Tavani A: Mediterranean diet and colorectal cancer risk: a pooled analysis of three Italian case-control studies. Br J Cancer 115: 862-865, 2016.

27 Giraldi L, Panic N, Cadoni G, Boccia S and Leoncini E: Association between Mediterranean diet and head and neck cancer: results of a large case-control study in Italy. Eur J Cancer Prev 26: 418-423, 2017.

28 Hodge AM, Bassett JK, Shivappa N, Hébert JR, English DR, Giles GG and Severi G: Dietary inflammatory index, Mediterranean diet score, and lung cancer: a prospective study. Cancer Causes Control 27: 907-917, 2016.

29 Toledo E, Salas-Salvadó J, Donat-Vargas C, Buil-Cosiales P, Estruch R, Ros E, Corella D, Fitó M, Hu FB, Arós F, GómezGracia E, Romaguera D, Ortega-Calvo M, Serra-Majem L, Pintó X, Schröder H, Basora J, Sorlí JV, Bulló M, Serra-Mir M and Martínez-González MA: Mediterranean Diet and Invasive Breast Cancer Risk Among Women at High Cardiovascular Risk in the PREDIMED Trial: A Randomized Clinical Trial. JAMA Intern Med 175: 1752-1760, 2015.

30 Filomeno M, Bosetti C, Bidoli E, Levi F, Serraino D, Montella M, La Vecchia C and Tavani A: Mediterranean diet and risk of endometrial cancer: a pooled analysis of three Italian casecontrol studies. Br J Cancer 112: 1816-1821, 2015.
31 Castelló A, Pollán M, Buijsse B, Ruiz A, Casas AM, BaenaCañada JM, Lope V, Antolín S, Ramos M, Muñoz M, Lluch A, de Juan-Ferré A, Jara C, Jimeno MA, Rosado P, Díaz E, Guillem V, Carrasco E, Pérez-Gómez B, Vioque J, Boeing H, Martín M and GEICAM researchers: Spanish Mediterranean diet and other dietary patterns and breast cancer risk: case-control EpiGEICAM study. Br J Cancer 111: 1454-1462, 2014.

32 Mourouti N, Kontogianni MD, Papavagelis C, Plytzanopoulou P, Vassilakou T, Malamos N, Linos A and Panagiotakos DB: Adherence to the Mediterranean diet is associated with lower likelihood of breast cancer: a case-control study. Nutr Cancer 66: 810-817, 2014.

33 Grosso G, Biondi A, Galvano F, Mistretta A, Marventano S, Buscemi S, Drago F, Praud D, Bertuccio P, Bosetti C, Turati F, Ferraroni M and La Vecchia C: Adherence to the Mediterranean diet and gastric cancer risk in Italy. Int J Cancer 134: 2935-2941, 2014.

34 Praud D, Bertuccio P, Bosetti C, Turati F, Ferraroni M and La Vecchia C: Adherence to the Mediterranean diet and gastric cancer risk in Italy. Int J Cancer 134: 2935-2941, 2014.

35 Buckland G, Ros MM, Roswall N, Bueno-de-Mesquita HB, Travier N, Tjonneland A, Kiemeney LA, Sacerdote C, Tumino R, Ljungberg B, Gram IT, Weiderpass E, Skeie G, Malm J, Ehrnström R, Chang-Claude J, Mattiello A, Agnoli C, Peeters PH, Boutron-Ruault MC, Fagherazzi G, Clavel-Chapelon F, Nilsson LM, Amiano P, Trichopoulou A, Oikonomou E, Tsiotas K, Sánchez MJ, Overvad K, Quirós JR, Chirlaque MD, Barricarte A, Key TJ, Allen NE, Khaw KT, Wareham N, Riboli E, Kaaks R, Boeing H, Palli D, Romieu I, Romaguera D and Gonzalez CA: Adherence to the Mediterranean diet and risk of bladder cancer in the EPIC cohort study. Int J Cancer 134: 2504-2511, 2014.

36 Kenfield SA, DuPre N, Richman EL, Stampfer MJ, Chan JM and Giovannucci EL: Mediterranean diet and prostate cancer risk and mortality in the Health Professionals Follow-up Study. Eur Urol 65: 887-894, 2014.

37 Idilbi NM, Barchana M, Milman U and Carel RS: Mediterranean diet in cancer patients and cancer free adult Arabs in Israel - a case-control study]. Harefuah 152: 385-388, 2013.

38 Bosetti C, Turati F, Dal Pont A, Ferraroni M, Polesel J, Negri E, Serraino D, Talamini R, La Vecchia C and Zeegers MP: The role of Mediterranean diet on the risk of pancreatic cancer. $\mathrm{Br} \mathrm{J}$ Cancer 109: 1360-1366, 2013.

39 Bamia C, Lagiou P, Buckland G, Grioni S, Agnoli C, Taylor AJ, Dahm CC, Overvad K, Olsen A, Tjønneland A, Cottet V, Boutron-Ruault MC, Morois S, Grote V, Teucher B, Boeing H, Buijsse B, Trichopoulos D, Adarakis G, Tumino R, Naccarati A, Panico S, Palli D, Bueno-de-Mesquita HB, van Duijnhoven FJ, Peeters PH, Engeset D, Skeie G, Lund E, Sánchez MJ, Barricarte A, Huerta JM, Quirós JR, Dorronsoro M, Ljuslinder I, Palmqvist R, Drake I, Key TJ, Khaw KT, Wareham N, Romieu I, Fedirko $\mathrm{V}$, Jenab M, Romaguera D, Norat $\mathrm{T}$ and Trichopoulou A: Mediterranean diet and colorectal cancer risk: results from a European cohort. Eur J Epidemiol 28: 317-328, 2013.

40 Buckland G, Travier N, Cottet V, González CA, Luján-Barroso L, Agudo A, Trichopoulou A, Lagiou P, Trichopoulos D, Peeters PH, May A, Bueno-de-Mesquita HB, Bvan Duijnhoven FJ, Key TJ, Allen N, Khaw KT, Wareham N, Romieu I, McCormack V, Boutron-Ruault M, Clavel-Chapelon F, Panico S, Agnoli C, Palli D, Tumino R, Vineis P, Amiano P, Barricarte A, Rodríguez L, Sanchez MJ, Chirlaque MD, Kaaks R, Teucher B, Boeing H, 
Bergmann MM, Overvad K, Dahm CC, Tjønneland A, Olsen A, Manjer J, Wirfält E, Hallmans G, Johansson I, Lund E, Hjartåker A, Skeie G, Vergnaud AC, Norat T, Romaguera D and Riboli E: Adherence to the mediterranean diet and risk of breast cancer in the European prospective investigation into cancer and nutrition cohort study. Int J Cancer 132: 2918-2927, 2013.

41 Kontou N, Psaltopoulou T, Soupos N, Polychronopoulos E, Linos A, Xinopoulos D and Panagiotakos DB: The role of number of meals, coffee intake, salt and type of cookware on colorectal cancer development in the context of the Mediterranean diet. Public Health Nutr 16: 928-935, 2013.

42 Cade JE, Taylor EF, Burley VJ and Greenwood DC: Does the Mediterranean dietary pattern or the Healthy Diet Index influence the risk of breast cancer in a large British cohort of women? Eur J Clin Nutr 65: 920-928, 2011.
43 Samoli E, Lagiou A, Nikolopoulos E, Lagogiannis G, Barbouni A, Lefantzis D, Trichopoulos D, Brennan P and Lagiou P: Mediterranean diet and upper aerodigestive tract cancer: the Greek segment of the Alcohol-Related Cancers and Genetic Susceptibility in Europe study. Br J Nutr 104: 1369-1374, 2010.

Received August 11, 2017

Revised October 6, 2017

Accepted October 11, 2017 